\title{
Kamu Binalarında Proje Dışı Kullanılan Elektrikli Cihazların Yangın Oluşumuna ve Elektrik Tüketimindeki Artışa Etkilerinin Belirlenmesi
}

\author{
Sema Yilmaz ${ }^{1 *}$, Cemil Sungur ${ }^{2}$ \\ ${ }^{1}$ Selçuk Üniversitesi, Bozkır Meslek Yüksekokulu, Elektrik ve Enerji Bölümü, Konya, Türkiye (ORCID: 0000-0000-0000-0000) \\ ${ }^{2}$ Konya Teknik Üniversitesi, Mühendislik ve Doğa Bilimleri Fakültesi, Elektrik-Elektronik Bölümü, Konya, Türkiye (ORCID: 0000-0000-0000-0000) \\ $\left(1^{\text {st }}\right.$ International Conference on Computer, Electrical and Electronic Sciences ICCEES 2020 - 8-10 Ekim 2020)
}

(DOI: 10.31590/ejosat.804388)

ATIF/REFERENCE: Yılmaz, S. \& Sungur, C. (2020). Kamu Binalarında Proje Dışı Kullanılan Elektrikli Cihazların Yangın Oluşumuna ve Elektrik Tüketimindeki Artışa Etkilerinin Belirlenmesi. Avrupa Bilim ve Teknoloji Dergisi, (Özel Sayı), 226-230.

$\ddot{O} \mathbf{z}$

Son yıllarda ülkemizde meydana gelen yangınların sebebi olarak teknolojinin gelişmesine bağlı olarak artan elektrikli cihazların kullanımı gösterilmekte ve yazılan raporlarda elektrik kontağından çıkan yangın ifadesi kullanılmaktadır.

$\mathrm{Bu}$ çalı̧̧mada kamu binalarında oluşabilecek elektrik enerjisi kaynaklı yangınlar için bir araştırma yapılmıştır. Bunun için kamu binalarında elektrik projesi dışında kullanılan elektrikli cihazların elektrik tesisatı üzerindeki olumsuz etkileri incelenmiştir. Bu olumuz etkilerin yanı sıra yıl içerisinde elektrik tüketimindeki artışlar ve bu artışların maddi olarak ülkemize getirdiği yük ve bundan elektrik tesisatının nasıl olumsuz etkilendiği belirlenmiştir.

Çalışmanın sonucunda pilot olarak seçilen kamu binasında, binanın inşası esnasında belirlenen elektrik projelerinin göz ardı edilerek proje dışı ve kontrolsüz alıcı elemanlar kullanılması bina kurulu gücünü artırmaktadır. Bina kurulu gücündeki artışlar mevcut enerji hatlarında aşırı yük, buna bağlı olarak aşırı ısınma ve yangına sebep olacağı belirlenmiştir. Ayrıca bu kontrolsüz enerji tüketiminin ciddi maliyet artı̧̧larına sebep olduğu gözlenmiştir.

Anahtar Kelimeler: Elektrik Enerjisi Tasarrufu, Su Isıtıcıları, Elektrik Sobaları, Demand Gücü, Kamu Binalarında Enerji Tasarrufu

\section{Determination of the Effects of Non-Project Electrical Devices on Fire Formation and Increase in Electricity Consumption in Public Buildings}

\begin{abstract}
The use of electrical devices, which has increased due to the development of technology, has been shown as the reason for the fires that have occurred in our country in recent years, and the term fire from the electrical contact is used in the reports written.

In this study, a research has been made for electrical energy fires that may occur in public buildings. For this, the negative effects of electrical devices used in public buildings other than the electrical project on the electrical installation have been examined.

In addition to these negative effects, it was determined that the increase in electricity consumption during the year and the financial burden that these increases brought to our country and how the electrical installation was affected negatively.

In the public building selected as a pilot as a result of the study, the use of off-project and uncontrolled receiver elements by ignoring the electricity projects determined during the construction of the building increases the building installed power. It has been determined that increases in the installed capacity of the building will cause excessive load on the existing power lines, resulting in overheating and fire. In addition, it was observed that this uncontrolled energy consumption caused serious cost increases.

In the public building selected as a pilot as a result of the study, the use of off-project and uncontrolled receiver elements by ignoring the electricity projects determined during the construction of the building increases the building installed power. It has been
\end{abstract}

\footnotetext{
* Sorumlu Yazar: Selçuk Üniversitesi, Bozkır Meslek Yüksekokulu, Elektrik ve Enerji Bölümü, Konya, Türkiye, ORCID: 0000-0000-0000-0000, semayilmaz@selcuk.edu.tr
} 
determined that increases in the installed capacity of the building will cause excessive load on existing power lines, resulting in overheating and fire. In addition, it was observed that this uncontrolled energy consumption caused serious cost increases.

Keywords: Electric Energy Saving, Water Heaters, Electric Stoves, Demand Power, Energy Savings in Public Buildings.

\section{Giriş}

Ülkemizde meydana gelen yangınların oluşumlarına sebep olarak elektrik kontağından çıkan yangın ifadesi sıkça kullanılmaktadır. Bu ifadelerin ne derece doğru olduğuna ve asıl sebebin ne olduğunu belirleme amacı ile bu araştırma yapılmıştır. Bunun için Örnek kamu binası olarak Konya ili Bozkır ilçesinde bulunan Cumhuriyet Ortaokulu seçilmiştir.

Seçilen pilot kamu binalarında, yönetmelik ve mevzuatlarda yeri olmamasına rağmen elektrikli isıtıcılar (soba, su 1sıtıcısı vb) klima, vantilatör gibi ortam soğutucuları mevcut olduğu görülmüştür. Bu cihazlar mevcut bina elektrik projesinde gösterilmediğinden bina elektrik tesisatında döşenen kabloların iletken kesitlerine yansıtılmazlar. Bu durum hem besleme trafolarında hem de kablolarda aşırı 1sınmaya sebep olmaktadır. Bu tür kablo ısınmaları binalarda yangına sebep olurlar (Anadolu Sigorta Bülteni, 2012).

Okullarda ilave yükler vardır. Bu yükler herhangi bir değer gözetilmeksizin, bölgemizdeki dağııım firması MEDAŞ’tan habersiz ve kontrolsüz olarak ek yapılan alıcı elemanlar aracılığı ile kullanılmaktadır (Aksoy, 2018). Bu durum linye hattının aşırı yüklenmesine, dolayısı ile kullanılan kablo direncinin ve izolasyonunun zayıflamasina neden olmaktadır. Okullara yapılan bu ek bağlantılar rastgele yetkisiz kişiler tarafından yapıldığı için kablo kesitleri de rastgele seçilmektedir (Resmî Gazete, 1996).

Çalışma yapılan Cumhuriyet Ortaokulunda ilave yüklerin durumu:

Kamu binalarında kontrolsüz kullanılan bu cihazların bir diğer etkisi ayrı bir sayaca bağlı olmayıp kamu binalarının elektrik enerjisini kullanmaktadırlar. Yani tükettikleri elektrik enerjisi kontrol altında olmayıp okul elektrik giderlerine dâhildir. Elektrikli ısıtıcılar ve soğutucular, birçok okulda ve kamu binalarında birden fazla vardır; proje dışı olduklarından dolayı kullanımları da kontrol altında değildir.

$\mathrm{Bu}$ cihazların tükettikleri elektrik miktarı ülke geneline oranlandığı zaman büyük miktarda elektrik enerjisi tüketimine sebep olmaktadırlar.

Bu örnek çalışmanın amacı;

1. Ülkemizdeki tüm kamu binalarında her mesai günü rahatlıkla kullanılan elektrikli isıtıcı kullanan çay ocakları, soğutucular (vantilatör, aspiratör), isıtıcılar (elektrikli sobalar) ülke genelinde büyük miktarda elektrik enerjisi miktarının -yönetmeliklerde olmamasına rağmen- devlet bütçesi tarafindan ödendiğine farkındalık oluşturmaktır.

2. Kamu binalarında elektrikli ısıtıcılar ve soğutucuların bir yıl içerisinde elektrik enerjisi tüketimini hesaplayarak oluşturacakları tehlike durumlarını ortaya çıarmaktır.

3. Elektrik tesisatına fazla yüklenilmesi sonucu meydana gelecek muhtemel yangınların önüne geçmektir.

4. Cihazların okullardan ve kamu binalarından kaldırılması ile sağlanan elektrik enerjisi tasarrufu ile ülke ekonomisine katkı sağlanacağını ispatlamaktır.

$\mathrm{Bu}$ amaçlar doğrultusunda bir uygulama çalışması gerçekleştirilmiş olup, elde edilen veriler istatistiksel analiz yöntemleri ile değerlendirilmiş ve yorumlanmıştır.

\section{Materyal ve Metot}

Kamu binalarında yapılan bu çalışmada, Konya İli, Bozkır İlçesi, İlçe Milli Eğitim Müdürlüğü'ne bağlı Cumhuriyet Ortaokulu pilot okul olarak incelenmiştir.

Çalışma kapsamında öncelikle cihazların bağlı olduğu elektrik tesisatının tamamının Elektrik İç Tesisat Yönetmeliğine uygun olup olmadığı incelenmiştir. Ana kolon. Kolon ve Linye hatlarının kablo kesitinin ve sigorta değerlerinin proje değerlerine uygun olup olmadığ 1 tespit edilmiştir.

Bozkır MEDAŞ İşletme Şefliği’nden pilot okulların demand güçleri istenilmiş olup ve dağıtım firması ile yapılan sözleşme gücü değerleriyle karşılaştırılarak güç aşımları tespit edilmiştir.

Aynı şekilde pilot okullarda çay ocağı, akıllı tahta, elektrik sobası, vantilatör, klima, vs. cihazların adedi, gücü ve kullanım süreleri de tespit edilip okul elektrik giderlerine etkileri hesaplanmıştır.

Tüm bunların sonucunda çıkan değerler 2017 yılına ait elektrik faturalarının da incelenmesi ile okul elektrik tüketimine etkisi belirlenmiştir. Elde edilen verilerle ısıtma, ısınma ve ortam soğutucu cihazların bir yılda tükettikleri elektrik enerjisi miktarı kwh cinsinden hesaplanmıştır.

\section{Araştırma Sonuçları ve Tartışma}

1. Bir adet 2750 watt gücündeki elektrikli ssıtıcı kış aylarında hafta içi 6 saat kullanılmaktadır. Bir yılda elektrikli isıtıcının ortalama 6 ay kadar kullanıldığı tahmin edilerek elektrikli ısıtıcının bir yıllık elektrik enerjisi tüketimi ortalama $1980 \mathrm{kwh}$ 
hesaplanmıştır (Tablo 1).

Tablo 1. Elektrikli Soba Yıllık Elektrik Tüketimi

\begin{tabular}{c|l|l|l|l|l}
\hline $\begin{array}{c}\text { Cumhuriyet } \\
\text { Ortaokulu }\end{array}$ & Adet & $\begin{array}{c}\text { Günlük Kullanım }- \\
\text { Saat }\end{array}$ & $\begin{array}{c}\text { Günlük kullanılan güç - } \\
\text { kwh }\end{array}$ & $\begin{array}{c}\text { Yılık Kullanım - } \\
\text { Gün }\end{array}$ & $\begin{array}{c}\text { Yıllık Elektrik Tüketimi - } \\
\text { kwh }\end{array}$ \\
\hline $\begin{array}{c}\text { Elektrikli Isıtıc1 } \\
\text { (soba, 5×550watt) }\end{array}$ & 1 & 6 & 2,75 & 120 & 1980 \\
\hline
\end{tabular}

2. Aynı okulda eğitim öğretim süresi boyunca hafta içi her gün, çay ocağı uzun süreli kullanılmakta olup suyun kaynama süresi boyunca ocağın 6,49 amper akım çektiği ölçülmüştür.

Gün içerisinde eklenen su miktarına ve kullanım süresine göre ocağın tam kapasite ile çalışma süresi hesaplanmıştır.

Buna göre çay ocağının yıllık elektrik enerjisi tüketimi 1708 kwh olarak hesaplanmıştır (Tablo 2). Tablodaki hesaplamaya resmî tatiller, 15 tatil ve yaz tatili dahil edilmemiştir.

Tablo 2. Elektrikli Çay Ocăğ Yıllık Elektrik Tüketimi

\begin{tabular}{c|c|c|c|c|c|c}
\hline Adet & $\begin{array}{c}\text { Çay Ocă̆ı Gücü - } \\
\text { watt }\end{array}$ & $\begin{array}{c}\text { Şebeke Gerilimi - } \\
\text { Volt }\end{array}$ & $\begin{array}{c}\text { Çalışma akımı - } \\
\text { Amper }\end{array}$ & $\begin{array}{c}\text { Günlük tüketim - } \\
\text { saat }\end{array}$ & $\begin{array}{c}\text { Yıllık Tüketim - } \\
\text { gün }\end{array}$ & $\begin{array}{c}\text { Yıllık Tüketim - } \\
\text { kwh }\end{array}$ \\
\hline 1 & 2000 & 220 & 6,47 & 6 & 200 & 1708,08 \\
\hline
\end{tabular}

3.Cumhuriyet Ortaokulunda 11 adet etkileşimli tahta mevcuttur. Bu tahtalar için ayrıca linye hattı çekilip sistem odası kurulduğu görülmüştür. Ancak okulun ana kolon hattının aynı kaldığg ve de elektrik dağıtım firması ile yeni bir sözleşme gücü belirleme yoluna gidilmediği belirlenmiştir.

Akıllı tahtaların haftalık kullanımı dersin konusuna ve ders hocasına göre değişmekle birlikte haftalık ders saatinin yarısı kadardır. Buna göre bir tahtanın haftalık kullanımı yaklaşık olarak 20 saat alınmıştır. Yapılan ölçümlere göre akıllı tahta ekran açıkken 1,2 amper, standbye konumunda ise 0,011 amper akım çekmektedir. Buna göre ekran açıkken etkileşimli tahta gücü yaklaş1k olarak 264 watt, standbye konumunda ise 2,42 watt olarak ölçülmüştür. Okulda bulunan 11 adet etkileşimli tahtanın yıllık elektrik enerjisi tüketimi ortalama $2090 \mathrm{kwh}$ olarak hesaplanmıştır.

Tablo 3. Etkileşimli Tahta Yıllık Elektrik Tüketimi

\begin{tabular}{|c|c|c|c|c|c|c|}
\hline Adet & $\begin{array}{c}\text { Akıllı Tahta Çekilen } \\
\text { Akım - Amper }\end{array}$ & $\begin{array}{c}\text { Akıllı Tahta } \\
\text { Gücü - Watt }\end{array}$ & $\begin{array}{c}\text { Haftalık } \\
\text { tüketim - saat }\end{array}$ & $\begin{array}{c}\text { Yıllık (36 hafta) } \\
\text { Kullanım - saat }\end{array}$ & $\begin{array}{c}\text { Bir Tahtanın Yıllık } \\
\text { ElektrikTüketimi - } \\
\text { kwh }\end{array}$ & $\begin{array}{c}\text { 11 Tahta Yılık Elektrik } \\
\text { Tüketimi - kwh }\end{array}$ \\
\hline 11 & 1,2 & 264 & 20 & 720 & 190,08 & 2090,88 \\
\hline
\end{tabular}

Cumhuriyet Ortaokulunda bulunan 11 adet etkileşimli tahta, bir adet elektrik sobası ve bir adet çay ocağının yıllık toplam elektrik enerjisi tüketimi yaklaşık olarak 5778,96 kwh hesaplanmıştır. Bu elektrik enerjisi inceleme yaptığımız okulda aşırı güç çekimine neden olmaktadır.

Aşırı güç çekimi elektrik dağıtım firması ile yapılan sözleşme gücünü dolayısı ile bina demand gücünü de artırmaktadır (Yılmaz, 2006).

Kullanıcı ile dağıtım firması arasında imzalanan anlaşma gücüne demand gücü denir (Resmî Gazete, 2003).

Dağıtım Şirketi, dağıtım sisteminin güvenliği üzerinde risk oluşturacak şekilde anlaşma gücünü aşan kullanıcıya, ihlalin sonlandırılması hakkına sahiptir (Resmî Gazete, 2017).

Tüketicilerin elektrik projesinde belirtilen kurulu güç harici fazla güç kullanım hakları \%20’dir (Resmî Gazete, 2007). Sözleşmede belirtilen güç değerlerinin üzerine çıkılması hem yasal değildir hem de tesisattaki kablo yalıtımlarında yer yer ısınmalara sebep olduğu için tehlikelidir (Resmî Gazete, 2011). Bu tür 1sınmalar elektriksel yangın nedeni olabilir (O’Connor ve Redsicker, 1987).

Okullarda kullanılan projelerde gösterilmeyen elektrikli cihazlar bina demand gücünü bir hayli artırmaktadır. Cumhuriyet Ortaokuluna ait olan elektronik sayaç bilgi dökümü Bozkır MEDAŞ İşletme Şefliği'nden alınan bilgiler doğrultusunda 2017 yılı içerisindeki demand güçleri Tablo 4'de gösterildiği gibidir (Bozkır Kaymakamlığı, 2018).

Tablo 4. Cumhuriyet Ortaokulu 2017 Yılı Demand Güçleri

\begin{tabular}{l|l|r|c}
\hline \multicolumn{1}{c|}{ Demand Değerleri } & Kodu & Demand $(\mathbf{k W})$ & Tarih ve Saati \\
\hline Güncel Max. Demand & 1.06 .2000 & 6,284 & $2018-02-05,09: 30$ \\
\hline Geçmiş 1.Ay & $1.6 .0 * 01$ & 9,596 & $2018-01-11,08: 00$ \\
\hline Geçmiş 2.Ay & $1.6 .0 * 02$ & 8,148 & $2017-12-28,08: 45$ \\
\hline Geçmiş 3.Ay & $1.6 .0 * 03$ & 9,164 & $2017-11-28,10: 00$ \\
\hline Geçmiş 4.Ay & $1.6 .0 * 04$ & 11,344 & $2017-10-17,10: 00$ \\
\hline Geçmiş 5.Ay & $1.6 .0 * 05$ & 3,396 & $2017-09-27,11: 00$ \\
\hline Geçmiş 6.Ay & $1.6 .0 * 06$ & 2,520 & $2017-08-17,13: 00$ \\
\hline Geçmiş 7.Ay & $1.6 .0 * 07$ & 2,500 & $2017-07-25,08: 15$ \\
\hline Geçmiş 8.Ay & $1.6 .0 * 08$ & 3,728 & $2017-06-02,11: 45$ \\
\hline Geçmiş 9.Ay & $1.6 .0 * 09$ & 7,668 & $2017-05-22,09: 45$ \\
\hline Geçmiş 10.Ay & $1.6 .0 * 10$ & 7,388 & $2017-04-11,10: 00$ \\
\hline
\end{tabular}




\begin{tabular}{l|l|r|l}
\hline Geçmiş 11.Ay & $1.6 .0 * 11$ & 10,088 & $2017-03-16,08: 45$ \\
\hline Geçmiş 12.Ay & $1.6 .0 * 12$ & 11,436 & $2017-02-06,09: 15$ \\
\hline
\end{tabular}

Normal şartlar altında okulun demand gücü $5 \mathrm{kw}$ olması gerekirken tablodan da görüldüğü üzere eğitim öğretim dönemlerinde güç aşımı iki katından daha büyük değerlere ulaştı̆̆ belirlenmiş̧ir.

Okulun güç aşımı, kablo dirençlerinin zayıflamasında dolayısı ile kablo izolasyonlarının deforme olmasında en büyük etkendir. Güç aşımını artıran cihazlar, okulda bulunan elektrikli çay ocağı, elektrik sobası ve 11 adet etkileşimli tahtadır. Bu okul 66 yıldır aralıksız eğitim öğretimin görüldüğü bir okul olup, ilçenin en eski okuludur. Okulun zamanla gelişen/değişen ihtiyaçlarının karşılanması için sürekli olarak bilgisayar, etkileşimli tahta, elektrikli ısıtıcı gibi cihaz alımları olmuştur.

Elektrik tesisatında kullanılan kablo izolasyon dirençlerinin zayıflaması, izolasyonlarının deforme olması elektriksel kaynaklı bir yangın çıkma ihtimalini artıracaktır.

Binada elektrik kullanımı sürekli artış gösterirken bina ana kolon hattı aynı kalmıştı. Ana kolon hattının değiştirilmesi olası bir yangın tehlikesini azaltacaktır (Meral ve diğerleri, 2009). Ancak bu hattın yönetmelikler gereği kolayca değiştirilmesi pek mümkün değildir. Şöyle ki, ana kolon hattının değiştirilmesi için bina elektrik tesisatı projesinin tekrar çizilmesi, kurulu gücün belirlenmesi ve dağıtım firması ile tekrardan sözleşme imzalanması gerekmektedir. Bu yenilemeler kullanıcılar için maddi külfet demektir.

Eğer dağıtım firması ile tüketiciler arasında yapılan sözleşmelerde ana kolon hattının kontrolü dağıtıcı firmaya verilirse, dağıtıcı firma gerekli gördüğü takdirde ana kolon hattını değiştirebilecektir. Bu da olası yangın tehlikelerini bertaraf edecektir.

Eski binalarda ana kolon hattının kontrolü her ne kadar dağııım firmasına ait olsa da bu hat tüketiciye ait bir hattır. Dolayısı ile dağıtım firmasının istediği zaman ana kolon hattında değişiklik yapması söz konusu değildir. Ancak artan bina yüküne göre ana kolon hattının aynı kalması binalar için çok ciddi bir tehlikedir. Ana kolon hattında fazla yükle birlikte faz-faz çakışması meydana gelirse yangın kaçınılmazdır.

Buna göre okullarda proje dışı kullanılan ve yüksek akım çeken cihazların kullanımı ile ilgili olarak gerekli düzenlemelerin bir an önce yapılması gerekmektedir. Bu düzenlemeler yapılamazsa alternatif çözümler üretilmesi zaruridir. Diğer okullarda ve bazı kamu binalarında da durum incelediğimiz okullardan farklı değildir.

$\mathrm{Bu}$ çalışmada yukarıda anlatılan durumlar göz önüne alınarak kamu binalarındaki ısıtma, ısınma ve diğer amaçlar için kullanılan cihazların kullanımı ile oluşabilecek tehlikeli durumlar anlatılmıştır. Bu cihazların harcadığı elektrik enerjisi sayısal değerlerle hesaplanmıştır. Bu cihazların kullanılmaması durumunda okul elektrik enerjisi giderlerinin azalacağı dolayısıyla ülke ekonomisine de katkı sağlanacağı belirlenmiştir.

Elektrik enerjisi tasarrufu yapılabilmesi ve de olası yangınların önüne geçilebilmesi için bu cihazların dağıtım firmasından ayrı bir hat çekilip ayrı bir sayaca bağlanılması gerekmektedir. Bunun bina elektrik tesisatında değişiklik yapmadan uygulanabilmesi için ayrıca bir yer (kantin ya da çay ocağı gibi) tahsis edilmesi gerekmektedir. Böylece alıcı elemanların bağlı olduğu priz linyeleri okul hattından ayrılmış olacaktır.

Kalorifer sistemi çalışan ve ortam ısısı normal olan okullarda gereksiz olarak elektrik sobası kullanılması tartışmaya açıktır.

Sözü edilen cihazların kullanılmaması gerekmektedir. Bu cihazlar kullanılmadığı zaman okullarda elektrik enerjisinden ne kadar tasarruf yapıldığı ortaya net olarak çıkacaktır.

\section{Sonuç}

Bozkır Cumhuriyet Ortaokulunda proje dışı ve kontrolsüz olarak kullanılan elektrikli cihazların yıllık elektrik enerjisi tüketimi yaklaşı olarak 5,778MWh hesaplanmıştır. Tüketilen bu elektrik enerjisinin maliyeti devlet tarafindan karşılanmaktadır.

Bozkır ilçe merkezinde bulunan Bozkır HES'in (Hidroelektrik Santrali) Kurulu Gücü 0,074 MW’tir. Bozkır Cumhuriyet Ortaokulunda bir yılda proje dışı kullanılan elektrik enerjisinin üretilebilmesi için Bozkır HES'in 78 saat tam kapasite ile çalışması gerekmektedir.

$\mathrm{Bu}$ durumda, tüm okullarda hatta tüm kamu binalarında gerekli önlemler, düzenlemeler yapılarak, acilen ilave yükler devreden kaldırılmalıdır.

Ülkemizde 20 yaşından büyük bütün kamu binalarında acilen elektrik tesisatının kanun ve yönetmeliklere uygun olup olmadığının incelenmesi gerekmektedir.

Diğer öneriler aşağıda sıralanmıştır.

1. Uzatma kabloları sadece geçici olarak kullanılmalıdır, uzatma kablosu görünmeyecek ve sıkışabilecek yerlere konulmamalidır.

2. Uzatma kabloları halı altı gibi hava ile temasının engelleneceği yerlerden geçirilmemelidir. Eğer uzatma kablosu kullanılacaksa düğmeli ve sigortalı olanı seçilmelidir.

3. Elektrik tesisatı zaman zaman bakım ve onarımdan geçirilmelidir. Bakım esnasında kablo ezilmeleri, gevşek bağlantılar vb. uygunsuz durumların tespit edilmesi ve değiştirilmesi olası bir yangını önleyecektir. 
4. Proje dışı cihaz kullanımının önüne geçilmesi için gerekli önlemler alınmalıdır (TBMM, 2001). Kurallara uymayanlar hakkında caydırıc cezalar uygulanmalıdır.

5. Mümkün olduğu kadar kablolara ek yapılmamalıdır. Mutlaka ek yapılması gerekiyorsa klemens kullanılmalıdır.

6. Çocukların bulunduğu kreş anaokulu, anasınıfı vb. yerlerde alıcı elemanlar kapalı tipte olmalıdır.

7. Elektrik tesisatının bakım ve kontrollerinde termal kameralar kullanılmalıdır. Termal kameralar oldukça etkin çözümler sağlayarak elektrik tesisatında ısınan bölgelerin tespit edilmesine olanak sağlamaktadır. Termal kameraların yaygınlaşması ile elektrik tesisatındaki zafiyetlerin tespiti de kolaylaşacaktır (Allianz Sigorta, 2014).

8. Dağıtım firmaları ve idarecilerin yönetmeliklere uyulması sağlanmalı kurallara uymayan kişiler için caydırıcı önlemler alınmalıdır (Selçuk Üniversitesi, 2007).

9. Binalarda branşman hattı sorumluluk, kontrol ve değişiklik yetkisinin dağııım firmalarına bırakılması muhtemel yangınların önüne geçecektir (Resmi Gazete, 2007).

10. En az 20 yaşındaki okullarda;

a. Yangın güvenliği araştırması yapılmalıdır ve bu okullarda özellikle priz bağlantılarının kontrolü acilen yapılmalıdır.

b. Tüm alıcı elemanların bağlantı ve kablo izolasyon kontrolü acilen yapılmalıdır.

11. Aynı sokak aynı cadde ve aynı mahallede çıkan yangınların acilen araştıılması gerekmektedir. Bunun için Büyükşehir Belediye İtfaiye Daire Başkanlıkları ile ortak çalışmalar yapılmalı ve bu tür yangınların tesadüf olup olmadığı araştırılmalıdır (Konya Büyükşehir Belediye Başkanlığı, 2018).

12. Elektrik tesisatına darbe koruma düzenleri ve trimbox gibi gerilim sönümleyici cihazların takılması faydalı olacaktır (Trimbox, 2017).

13. Tüm kamu binalarında çay ocaklarının okul elektrik hattından ayrılması bina yükünü ve olası yangın tehlikesini azaltacaktır.

Sonuç olarak elektriksel yangınlar özellikle de güç aşımı sonucu kablo 1sınmaları ile oluşan kısa devre yangınları doğal afet değildir, gerekli tedbir ve önlemler alındığı takdirde önlenebilir.

\section{TEŞEKKÜR}

Bu makale 17401186 nolu BAP projesinden yayımlanmıştır. Bu çalışmaya, desteklerinden dolayı Bozkır Kaymakamı'na, Bozkır İlçe Milli Eğitim Müdürü’ne teşekkür ederim.

\section{Kaynakça}

Anadolu Sigorta Bülteni. (2012), İşletmelerde Elektrik Sistemleri Kaynaklı Yangınlar ve Yangınlara Karşı Alınabilecek Önlemler, 22 Mayıs 2018 tarihinde http://anadolurisk.com.tr/tr/bulten/isletmelerde-elektrik-sistemleri-kaynakli-yanginlar-ve-yanginlara-karsialinabilecek-onlemler adresinden alınd.

Yilmaz, Z. (2006), Akilli binalar ve yenilenebilir enerji. Tesisat Muhendisligi Dergisi, (91), 7-15.

Meral, M. E., Ahmet, T., ve Tümay, M. (2009), Elektrik tesislerinde enerji verimliliği. Uludağ University Journal of The Faculty of Engineering, 14(1).

Aksoy, A. (2018). Elektrik Kaynakll Yangınlar. https://aktif.net/tr/Aktif-Blog/Teknik-Makaleler/Elektrik-Kaynakli-Yanginlar

Redsicker, David R., ve O’Connor, John J. (1996) Practical Fire and Arson Investigation. CRC Press.

Anadolu Sigorta Bülteni (t.y.) İşletmelerde Elektrik Sistemleri Kaynaklı Yangınlar ve Yangınlara Karşı Alınabilecek Önlemler 22 Mayıs 2018 tarihinde http://anadolurisk.com.tr/tr/bulten/isletmelerde-elektrik-sistemleri-kaynakli-yanginlar-ve-yanginlara-karsialinabilecek-onlemler adresinden alınd.

Resmi Gazete, (1996), Elektrik $\dot{I}_{\zeta} \quad$ Tesisleri Yönetmeliği, $10 \quad$ Mayı 2018 tarihinde http://www.emoorg.tr/mevzuat/mevzuat_detay.php?kod=65 adresinden alındı.

Resmi Gazete (2011), Enerji Kaynaklarının ve Enerjinin Kullanımında Verimliliğin Artırlmasına Dair Yönetmelik, 21 Mayıs 2018 http://www.mevzuat.gov.tr/Metin.Aspx?MevzuatKod=7.5.15437\&Mevzuatlliski=0\&sourceXmlSearch= adresinden alınd1.

Resmi Gazete, (2007), Tasarruf Tedbirleri Genelgesi, 20 Eylül 2018 tarihinde http://www.resmigazete.gov.tr/eskiler/2007/01/20070118-13.htm adresinden alındı.

$\begin{array}{llllllll}\text { Selçuk Üniversitesi, } & \text { (t.y), Tasarruf } & \text { Tedbirleri, } & 27 & \text { Mays } & 2018 & \text { tarihinde }\end{array}$ https://www.selcuk.edu.tr/dosyalar/files/104/Tasarruf\%20Tedbirleri.pdf adresinden alındı.

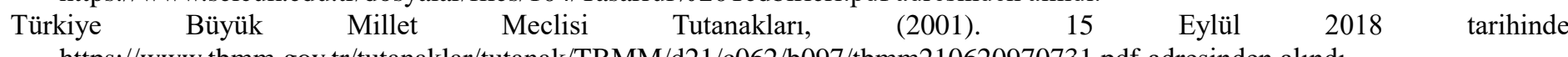
https://www.tbmm.gov.tr/tutanaklar/tutanak/TBMM/d21/c062/b097/tbmm210620970731.pdf adresinden alınd1.

Resmi Gazete, (2003), Elektrik $\dot{I}_{c ̧}$ Tesisleri Proje Hazırlama Yönetmeliği Proje Aşamaları, 21 Ekim 2018 tarihinde http://www.resmigazete.gov.tr/eskiler/2003/12/20031203.htm adresinden alındı.

Allianz Sigorta, (2014), Elektrik Nedenli Yangınlar, 27 Mayıs 2018 https://www.allianzsigorta.com.tr/tr/hakkimizda/riskmuhendisligi/risk-konulari/Diger-Riskler/Elektrik-Nedenli-Yanginlar/ adresinden alındı.

Elektrik Yangını Nasıl Çıkar ve Nasıl Önlenir, (2017). 27 Mayıs 2018 https://trimbox.com.tr/elektrik-yangini-nasil-cikar-ve-nasilonlenir adresinden alındi.

Bozkır Kaymakamlığı, (2018), Bilgi İhtiyacı, Sayı: 19923680-492-E.274.

Resmî Gazete, (2017), Enerji Piyasası Düzenleme Kurumundan, Elektrik Piyasası Bağlantı ve Sistem Kullanım Yönetmeliği, 28 Ekim 2018 tarihinde http://www.resmigazete.gov.tr/eskiler/2017/06/20170601-9.htm adresinden alındı.

Konya Büyükşehir Belediye Başkanlığı, (2018), Yangın İstatistik Bilgileri, Sayı: 51916638-622.01-1162-10716. 